\title{
A QUALIDADE DE SERVIÇOS EM DUAS UNIDADES DE ATENDIMENTO INTEGRADAS DO ESTADO DE MINAS GERAIS NA PERCEPÇÃO DE SEUS USUÁRIOS
}

\author{
Régis Cleber Fernandes de SOUSA ${ }^{1}$ \\ Mauro Calixta TAVARES ${ }^{2}$ \\ José Antônio de SOUSA NETO \\ Henrique Cordeiro MARTINS ${ }^{4}$
}

\begin{abstract}
'Mestre em Administração (FPL, 2014), e-mail regisadministrador@oi.com.br.
2Doutor em Administração (FEA/USP, 1996), e-mail maurocalixta@ terra.com.br.

${ }^{3} \mathrm{PhD}$ em Accounting and Finance (The University of Birmingham, 2001). E-mail: jose.antonio.neto@terra.com.br.

4Doutor em Administração (UFMG, 2005), e-mail: henrique.martins@ @umec.br.
\end{abstract}

\section{Recebido em: 30/05/2014 - Aprovado em: 15/09/2014 - Disponibilizado em: 15/12/2014}

Resumo: Crescentes demandas sociais têm levado os órgãos públicos e privados a reorientar seus esforços para conhecerem e atenderem melhor seus clientes/usuários. Além de torná-los mais eficientes na oferta e prestação de serviços, a boa qualidade pode se tornar um diferencial para o aumento da satisfação dos clientes/usuários. O objetivo deste estudo é analisar comparativamente, por meio da escala SERVQUAL, as expectativas e as percepções de clientes/usuários sobre a qualidade de serviços de duas unidades de atendimento - uma de gestão pública (UAI pública) e outra de gestão privada (UAI privada), através de parceria público-privada (PPP) - ambas do Estado de Minas Gerais. A metodologia deste estudo possui caráter descritivo de natureza quantitativa. Seu delineamento é do tipo levantamento com a utilização de questionários estruturados. As informaç̃os foram coletadas de 348 clientes/usuários divididos igualmente entre as duas unidades, que participaram da pesquisa respondendo a dois questionários baseados no modelo SERVQUAL, que analisaram as diferenças entre as expectativas e as percepções da qualidade de serviços. A hipótese é a de que os resultados obtidos neste estudo revelar possíveis diferenças de expectativa sobre a qualidade dos serviços prestados pelas duas UAIs, expectativa sobre a qualidade dos serviços analisados, evidenciando ainda a necessidade de ajustes posteriores sobre a sua qualidade de serviços.

Palavras-chave: Qualidade de serviços, Expectativa, Percepção e Parceria público-privada.

Abstract: The competitiveness and increasing social demands has led public and private agencies to redirect their efforts to know and meet their customers / users better. The good quality of services can make a difference to increase customer satisfaction and to make them more competitive in the pursuit of their goals in its provision and offer to the taxpayer. The aim of this study was to comparatively analyze the expectations and perceptions of service quality between a unit of public integrated care and through public-private partnership in Minas Gerais State through the SERVQUAL scale. The methodology of this study has a descriptive quantitative characteristic. The design is a type of survey that uses a structured questionnaire. The survey was conducted with customers / users of public UAI and private UAI managed through a Public Private Partnership (PPP). For gathering the information, in the UAIs, 348 customers / users were divided equally between the two units and they participated in the study by answering two based on SERVQUAL model. These questionnaires analyzed the differences between expectation and perception of the service quality. The results of this study revealed possible differences in expectations about the quality of services provided by the two Units of Integrated Care, the expectation about the quality of the services analyzed, and also the need for further adjustments on their quality of service.

Key words: Service quality; Expectations; Perceptions; Public Private Partnership (PPP) 


\section{INTRODUÇÃO}

A sociedade atual aponta de forma significativa para a importância da qualidade em serviços e para a forma como as empresas e os serviços públicos devem atuar a fim de alcançar a excelência na prestação desses serviços (MUNRO, 1994). Para Abrams, Ayers e Petterson (1986), a percepção da qualidade baseia-se em critérios objetivos e subjetivos. Conhecer a percepção dos usuários/clientes a respeito da qualidade do serviço pode ser um primeiro passo para o desenvolvimento de ações que levarão as empresas a melhorias, através do direcionamento e aperfeiçoamento de suas estratégias e ações.

Outro ponto importante é conhecer as reais necessidades dos serviços por parte dos próprios usuários/clientes. Entendendo também as expectativas de qualidade de seus serviços ofertados, os empresários estarão mais preparados para atender e entregar serviços com qualidade superior ao esperado (LAS CASAS, 2000)

O setor de serviços tem se beneficiado de experimentos antes desenvolvidos e praticados por setores tradicionais, como o militar e industrial, consolidando ainda mais o seu crescimento na economia, sendo fonte representativa de crescimento na economia brasileira e internacional (GRÖNROOS, 1995). Soares (2013) informa que "O setor de serviços, é o maior peso na economia (superior a $60 \%$ ), registrando também uma leve expansão de $0,01 \% "$.

Em Minas Gerais, a partir da primeira década do século XXI, o governo do estado, preocupado com esta nova tendência, criou o projeto Unidade de Atendimento Integrada (UAI), propondo um espaço onde se ofertasse uma gama de serviços públicos de todas as esferas públicas e de necessidade básica para a população.

Esse projeto passou por diferentes fases de gestão até ser concedido à participação privada, através de edital público de licitação, como parceria entre o governo e a iniciativa privada. Neste cenário de profundas transformações na gestão pública do estado, dentre muitos projetos do governo na busca para dar mais eficiência administrativa aos órgãos, tendo o cidadão como maior interessado; esta pesquisa pretende, partindo da percepção do usuário/cliente, analisar comparativamente, por meio da escala SERVQUAL, as expectativas e 
percepções da qualidade de serviços entre uma instituição pública e outra privada, ambas prestadoras dos mesmos tipos de serviço público.

Berry e Parasuraman (2006) afirmam que a confiança dos clientes pode ser afetada negativamente, quando as organizações ofertam serviços de forma descuidada e cometem erros que poderiam ser evitados. Não somente a confiança dos clientes, mas também a imagem da empresa e de seu projeto fica comprometida, colocando em dúvida a excelência de seus serviços.

Com base nesta afirmação, este estudo possui o intuito de ampliar a discussão sobre a qualidade de serviços públicos ofertados pela UAI, com gestões diferenciadas. Assim, pretendese responder ao seguinte questionamento: Qual a percepção dos usuários/clientes dos serviços públicos da UAI, nos dois modelos de gestão, estatal e através de parceira públicoprivada, quanto à qualidade dos serviços ofertados?

Assim, este estudo considera que a pesquisa é uma oportunidade de aprofundar seus conhecimentos quanto à importância da qualidade nos serviços públicos através da percepção dos usuários/clientes, ofertados nos dois modelos de gestão das UAIs. E também contribui para o entendimento sobre a qualidade de serviços e sua importância para o desenvolvimento organizacional, seja o destinatário a sociedade, o meio acadêmico ou as empresas prestadoras de serviços públicos.

\section{REVISÃO DE LITERATURA}

\subsection{Serviços e suas características}

Segundo Kotler (2000), os serviços são qualquer ato desempenhado que seja totalmente intangível e que não resulte na posse de algo material. Já Las Casas (2000) os define como atos, ações e desempenhos que são vivenciados e podem estar associados à transferência de um bem. Para Zeithaml e Bitner (1990), serviços são ações, processos e atuações; incluindo todas as atividades econômicas cujo produto não é algo físico, sendo normalmente consumido no momento em que é produzido, além de proporcionar valor agregado como conveniências, entretenimento, oportunidades, conforto ou saúde.

No entendimento de Grönroos (1995), serviço é uma atividade de natureza mais ou menos intangível, que 
normalmente,

mas

não

obrigatoriamente, acontece durante a interação entre o cliente e o prestador de serviço e/ou recurso físico e/ou sistema do fornecedor que atuam na solução dos problemas dos clientes. O autor afirma ainda que o serviço pode estar separado da presença do cliente. Serviços são intangíveis quando constituem experiências que o cliente vivencia. A intangibilidade torna difícil para os gerentes, funcionários e para os clientes avaliarem o resultado e a qualidade do serviço. Embora haja exceções, os serviços são de difícil padronização.

Além disso, afirma Cobra (1990), não podem ser provados, apalpados, ouvidos ou cheirados antes de serem comprados. Pela impossibilidade de avaliação do serviço antes da compra e pela dificuldade de apuração de seus resultados, os clientes percebem mais riscos na compra de serviços do que de produtos (GIANESI; CORRÊA, 1994).

A variabilidade dos serviços é uma característica marcante, como afirma Cobra (1990), quando são executados de forma artesanal; e tendem a variar quanto à forma como são realizados, exceto quando feitos por máquinas, de maneira informatizada, diminuindo-se assim as distorções e a falta de padronização. Las Casas (2000) afirma que, no entanto, o treinamento e a padronização dos recursos materiais podem contribuir para diminuir esta variação.

Os serviços, por serem intangíveis, apresentam também a característica de perecibilidade, em função de serem produzidos no momento em que são consumidos Nem mesmo podem ser estocados como produtos tangíveis, como afirma Kotler (1998). Por isso e para suprir as demandas, é necessário elaborar um planejamento para estar preparado com a quantidade e qualidade de serviços com que a empresa pretende trabalhar ou que o mercado quer e pode absorver (LAS CASAS, 2000)

\subsection{Classificação de serviços}

Segundo Gianesi e Corrêa (1994), as principais dimensões dos serviços que afetam a gestão de suas operações são:

- A ênfase dada às pessoas ou a equipamentos no processo: processos baseados em pessoas são, em geral, mais flexíveis do que processos baseados em equipamentos, mais adequados à padronização.

- O grau de contato com o cliente: as operações de alto contato, 
devido à presença do cliente, têm um ambiente mais carregado de incerteza e variabilidade, resultando em menor produtividade e controle mais difícil. O setor que realiza operações de alto contato com o cliente é normalmente chamado de front office, ou linha de frente; enquanto aquele que realiza operações de baixo contato denomina-se backroom ou retaguarda;

- O grau de participação do cliente no processo: os serviços podem ser vistos como uma sequência de transações, as quais podem se classificar em algum ponto entre os seguintes extremos: serviço total, em que todas as atividades são executadas pelo servidor, seja em front office ou backroom; e self-service, em que quase todas as atividades são executadas pelo cliente, cabendo ao servidor apenas a preparação;

- O grau de personalização do serviço: personalizar o serviço significa montar um pacote de serviços visando atingir as necessidades e expectativas de um cliente específico. O grau de personalização pode variar desde o aumento de opções padronizadas até a resposta perfeita a necessidades especificas de determinado cliente.

- O grau de julgamento pessoal dos funcionários: refere-se à autonomia do pessoal de contato com os clientes para atender suas necessidades e expectativas. Processos em que há alto grau de julgamento pessoal dos funcionários oferecem mais personalização aos clientes.

- O grau de tangibilidade do serviço: refere-se à relevância do bem facilitador no pacote produto/serviço. Esta dimensão ajuda a definir se o processo se aproxima mais do serviço puro ou da manufatura, colocando a ênfase mais no processo ou no produto, respectivamente.

\subsection{Classificação dos processos de serviços}

Corrêa e Caon (2006) apresentam a seguinte classificação dos processos de serviços:

- Serviços de massa: serviços em que grande número de clientes é atendido por dia numa unidade 
típica, de forma padronizada, visando a ganhos de escala. A grande ênfase está nas atividades de controle, feitas em back office;

- Serviços profissionais: serviços prestados diariamente, de forma completamente customizada, com atendimento personalizado e ajuste do pacote de serviço às necessidades e desejos de cada cliente por dia;

- Serviços de massa "customizados": serviços que se encontram numa posição próxima à posição de volume correspondente à dos serviços de massa, cria no cliente, de forma automatizada, uma sensação de serviço customizado;

- Serviços profissionais de massa: correspondente à anterior, há uma região que apresenta contínuo volume e é próxima à região de serviços profissionais, e que requerem personalização, procura aumentar seus ganhos de escala, a fim de atender a um número maior de clientes por dia em suas unidades de operação;

- Loja de serviços: é como se encontra, talvez, a maioria das operações de serviços. São operações que tratam um volume intermediário de clientes por dia em suas unidades de operação típicas, ficando a meio caminho quanto às variáveis customização, front office versus back office,

Para Parasuraman, Zeithaml e Berry (1988, p. 13), existem três características principais dos serviços que devem ser abordadas:

- Simultaneidade: serviços são consumidos simultaneamente ao momento em que são produzido, tornando difícil ou quase impossível detectar e corrigir as falhas antes que elas ocorram e afetem o cliente.

- Intangibilidade: os serviços representam um produto não físico, ou seja, não podendo ser transportados e/ou armazenados;

- Heterogeneidade: a grande variedade de serviços existentes e o forte relacionamento com o fator humano dificultam a atividade de padronização e estimação de preços.

\subsection{Qualidade na prestação de serviços}

Para Paladini (2000), é possível afirmar que qualidade é um conceito 
dinâmico, ou seja, que trabalha com referenciais que mudam ao longo do tempo e, às vezes, de forma bastante acentuada. Qualidade é, também, um termo de domínio público, pois todos têm uma noção intuitiva do que seja qualidade.

Para Johnston e Clark (2002), a diferença fundamental na prestação de serviços encontra-se na subjetividade e na dificuldade de estabelecer o que é qualidade, uma vez que os clientes reagem diferentemente ao que parece ser o mesmo serviço. Cada cliente possui uma determinada percepção sobre qualidade e, muitas vezes, essa diferença implica até mesmo o "estado de espírito do cliente" no momento da prestação de serviço. A intangibilidade, juntamente com a necessidade da presença do cliente e a simultaneidade da produção e consumo do serviço formam as principais características especiais das operações que irão definir a avaliação dos resultados e a qualidade dos serviços prestados. Entretanto, muitas vezes, essa avaliação é dificultada pela intangibilidade, uma vez que é difícil a padronização, tornando a gestão do processo mais complexa (GIANESI; CORRÊA, 1996).

Portanto, em serviços é fundamental que se controlem ou se realimentem os processos em função das necessidades dos clientes. As relações diretas com os clientes são enfatizadas, porque o cliente participa do processo produtivo de forma efetiva; e assim as organizações precisam ser flexíveis e possuir capacidade para mudança e renovação constantes (PALADINI, 2000).

Grönroos (1995) afirma que os consumidores escolhem prestadores de serviços comparando as percepções que têm do serviço recebido com o serviço esperado, o que é chamado de qualidade de serviço percebida. Bons resultados na qualidade percebida são obtidos quando os serviços recebidos ou experimentados atendem as expectativas dos clientes. $\mathrm{O}$ autor conclui que somente quando o prestador de serviços entende como os serviços serão avaliados pelos clientes é que é possível saber como gerenciar tais avaliações e como influenciá-las na direção desejada.

Zeithaml, Parasuraman e Berry (1990) atribuem a qualidade de serviços à discrepância entre as expectativas e as percepções dos clientes sobre um serviço experimentado. A chave para assegurar uma boa qualidade de serviço é obtida quando as percepções dos clientes excedem suas expectativas. 
Porém não basta compreender a importância de fornecer serviços com excelente qualidade; é preciso que haja um processo contínuo de monitoração das percepções dos clientes sobre essa qualidade, de identificação das causas das discrepâncias encontradas e da adoção de mecanismos adequados para a melhoria.

\subsection{Avaliação da qualidade do serviço pelo cliente}

Percebe-se, dentre as várias características de serviços, a de que estes dificilmente podem ser avaliados antes da compra, dando-se a avaliação durante o processo de prestação de serviço. Para Gianesi e Corrêa (1994), a avaliação que o cliente faz, durante ou após o término do processo, ocorre através da comparação entre o que ele esperava do serviço e o que ele percebeu do serviço prestado. Por serem os serviços intangíveis, a formação das expectativas do cliente antes da compra não tem como se basear em uma imagem real; depende, entre outros fatores, da comunicação transmitida aos consumidores.

Desse modo, uma afirmativa exagerada de uma empresa seguradora do tipo "em caso de acidente você será ressarcido imediatamente", pode realmente gerar expectativas que excedem aquelas que poderão ser atendidas pelo fornecedor do serviço.

Assim, percepção que o cliente tem do serviço prestado é formada por dois fatores: a prestação do serviço e a comunicação transmitida ao cliente. Esses dois fatores são importantes para a percepção do serviço, pois muitas vezes os clientes não estão cientes de tudo o que acontece no sistema de operações, principalmente no back room.

Em seu estudo sobre a área de saúde, Donabedian (1980) classificou a qualidade em três dimensões: técnica, interpessoal e ambiental. A técnica se refere à aplicação atualizada dos conhecimentos científicos na solução do problema do cliente/usuário. A interpessoal diz respeito à relação que se estabelece entre o prestador de serviços e o cliente/usuário. A ambiental concerne às comodidades, como conforto e bem-estar, oferecidos ao cliente.

No entanto, algumas características das organizações públicas tornam difícil a avaliação interna dos resultados obtidos por elas, sendo uma delas a premissa de que seus trabalhadores fazem o melhor que pode ser feito (MUNRO, 1994). Nesse 
sentido, as melhores ideias para aprimorar os serviços, segundo Slack (1997) derivam dos próprios clientes ou usuários dos serviços. São eles que melhor podem julgar a qualidade percebida dos serviços públicos e também sugerir ideias úteis de melhoria contínua.

\subsection{Método SERVQUAL}

Segundo Campos (2004), a palavra método vem do grego e é a soma das palavras gregas Meta e Hodós, sendo que Hodós significa caminho. Portanto, método significa: "caminho para a meta". Dessa forma, o método mostrará o caminho que deverá ser utilizado para analisar comparativamente, por meio da escala SERVQUAL, as expectativas e percepções da qualidade de serviços entre uma instituição pública e outra privada prestadoras de serviços públicos.

O primeiro modelo específico para avaliação de serviços pode ser atribuído ao trabalho dos pesquisadores norte-americanos

Zeithaml, Parasuraman e Berry (1990), que o desenvolveram visando captar critérios para a avaliação da qualidade em serviços. De acordo com eles, os usuários avaliam a qualidade comparando o que desejam ou esperam do serviço com aquilo que obtêm.

No modelo mencionado, os critérios de avaliação aplicados levam em consideração as brechas, as lacunas e os hiatos (gaps), que são as diferenças entre as expectativas dos usuários e o que é realmente oferecido. Esses gaps representam grandes obstáculos à tentativa de se atingir um nível de excelência na prestação de serviços (ZEITHAML; PARASURAMAN; BERRY, 1990).

A partir do modelo conceitual dos "gaps", Zeithaml, Parasuraman e Berry (1990) desenvolveram a escala SERVQUAL para mensuração das percepções dos clientes sobre a qualidade de serviços. Para Berry, Parasuraman e Zeithaml (2006), a qualidade percebida significa um julgamento global que o cliente faz da excelência ou superioridade do serviço, sendo uma forma de atitude relacionada, mas não equivalente, à satisfação, e que resulta de uma comparação entre as expectativas e as percepções de performance do serviço.

Conhecida por sua aplicabilidade, bem como pelo poder de diagnóstico, a escala SERVQUAL tem sido amplamente difundida e utilizada 
ZEITHAML, 2006). Seus criadores sugerem que ela deve ser devidamente adaptada 30 a cada caso, considerando o tipo de negócio e os atributos mais relevantes; como foi feito no presente estudo, passando de 5 para 6 as dimensões de qualidade, e de 22 para 27 perguntas, avaliadas em uma escala de Likert de 5 pontos.

Com base nessas 5 dimensões, encontra-se a diferença entre os escores de percepção e os de expectativa para determinar a mensuração da qualidade do serviço percebida pelo cliente. Logo, se a expectativa do serviço for superior à percepção, a qualidade percebida pelo usuário estará abaixo do grau esperado, ou seja, a diferença será negativa; e para que a diferença seja positiva, a percepção deve ser maior que a expectativa, o que indica uma qualidade acima do esperado (JOHNSTON; CLARK, 2002). "A chave para um serviço de alta qualidade radica em equilibrar as expectativas e as percepções", de acordo com Parasuraman, Zeithaml e Berry (1985).

Corrêa e Caon recomendam que, antes de aplicar o instrumento SERVQUAL em uma unidade de serviço, como, por exemplo, a UAI, "seja realizado o mapeamento do processo para melhor identificar as dimensões de qualidade, identificando as atividades de front office, criando um ciclo de serviço" (2006, p. 104).

Assim, acredita-se que, aplicando esse instrumento em dois setores, ambos prestadores de serviço público, mas com gestões diferentes, atingir-se-á o objetivo de mensurar a percepção de qualidade. Convém ressaltar a importância de se avaliar o serviço prestado pela UAI, cada vez mais presente no rol de atividades de serviços sendo oferecidos em nossa sociedade.

\subsection{Serviços públicos}

O serviço público é de fundamental relevância para a sociedade, podendo ser considerado toda atividade ofertada de utilidade material e destinada à satisfação da coletividade, mas de fruição singular pelos administrados. O Estado assume essa atividade como pertinente a seus deveres, prestando-a por si mesmo ou por quem lhe faça as vezes, sob um regime de Direito Público.

Para Mello (2004), Como toda e qualquer noção jurídica, este serviço público só tem préstimo e utilidade se corresponder a um dado sistema de princípios e regras; isto é, a um regime, a uma disciplina peculiar. Daí que só 
merece ser designado como serviço público aquele concernente à prestação de atividade e comodidade material fruível singularmente pelo administrado, desde que tal prestação se conforme a um determinado e específico regime: o regime de Direito Público, o regime jurídico administrativo.

A Constituição Federal de 1988 estabelece em seu art. 37 que a prestação de serviços públicos não é mera faculdade do Estado. Ele tem não somente o dever, mas a obrigação de assegurar, garantir e prestar todos os serviços ditos públicos. $\mathrm{O}$ serviço público deve conter todos os elementos característicos que o configuram, assim como as responsabilidades pela sua execução devem ser prestadas pelo Estado, sendo regido pelo regime jurídico de direito público, de caráter geral, e decorrente de lei como uma obrigação para o Estado. De acordo com o art. 175 da Constituição Federal: "Incumbe ao Poder Público, na forma da lei, diretamente ou sob regime de concessão ou permissão, sempre através de licitação, a prestação de serviços públicos" (BRASIL, 1988).

\subsubsection{Administração pública No} entendimento

No entendimento de Castor $e$ outros (1987), a administração pública reage de forma lenta e insatisfatória às mudanças econômicas e sociais que se processam à sua volta, tornando mais agudas e sensíveis suas distorções e deficiências. Kliksberg compartilha desse ponto de vista, ao afirmar que a administração burocrática no serviço público, embora tenha sido criada para esse fim, não garante nem rapidez, nem boa qualidade, nem custo baixo para os serviços prestados ao público, sendo na verdade lenta, cara, autorreferida e pouco ou nada orientada para o atendimento das demandas dos cidadãos.

Partindo do pressuposto de que as mudanças nas organizações públicas devem atender as necessidades reais de seus clientes, Caulliraux e Yuki (2004) definem o modelo gerencial como aquele em que o objetivo é "oferecer serviços públicos de maior qualidade, atendendo melhor às demandas dos seus usuários" (2004, p. 32).

\subsubsection{Mudanças na gestão pública brasileira}

Nas últimas décadas muito se tem avançado na administração privada, devido ao aparato empresarial 
necessariamente visar ao ganho através do lucro. Melo (2004) define que administrar não é somente prestar serviços; é também executar, dirigir, governar e exercer a vontade com objetivo de obter um resultado útil; administrar quer dizer, para o autor, traçar um programa de ação e executálo.

Diferentemente, a administração pública, em sua essência, não tem o lucro como alvo, afirmam BresserPereira e Spink (2008); seu objetivo "é o interesse público", não deixando de se pautar pela eficiência na prestação dos serviços públicos à sociedade. Assim se apregoa no art. 37 da Constituição Federal (BRASIL, 1988), dispositivo que formaliza e dá as diretrizes da gestão pública no Brasil, baseada nos princípios da legalidade, publicidade, impessoalidade e de eficiência, objetivando uma gestão eficaz em todas as esferas governamentais.

O cumprimento dos princípios da administração pública brasileira, tendo a eficiência como foco, possibilita à administração a busca por melhores resultados, assim como na administração privada, impondo-lhe responsabilidades de retorno positivo em seus serviços ofertados à sociedade com mais rapidez, eficiência e eficácia funcional, como afirma Moore (2002).

\subsubsection{Novas formas de se pensar a administração pública}

Por volta de 1980, por razões de ordem política, jurídica e financeira, passou a ser objetivo de diversos países a diminuição do tamanho do Estado. De acordo com Caulliraux e Yuki (2004), foi formulado um modelo que buscava realizar reformas consideradas essenciais para que os países em desenvolvimento conseguissem superar as crises econômicas e trilhassem o destino do crescimento sustentável.

Esse modelo surgiu como resultado de um evento que pode ser considerado um marco histórico: a reunião realizada pelo International Institute for Economy (IIE), na capital dos Estados Unidos, em novembro de 1989, e que se tornou mundialmente conhecida como o Consenso de Washington.

Para Abrúcio (in BRESSERPEREIRA, 2010), o processo de privatizações no Brasil teve início nos anos 80 do século $\mathrm{XX}$, numa fase que se caracterizou pela privatização de empresas, que em razão da existência de problemas financeiros haviam sido anteriormente absorvidas pelo Estado. Essa etapa atingiu empresas de pequeno porte com resultados modestos, tendo 
como principal objetivo a limitação da presença do Estado no setor produtivo.

Em 1990, a Lei Federal $n^{\circ}$ 8.031/90 criou o Plano Nacional de Desestatização (PND), deixando clara a intenção do Estado de implementar um programa de privatização em larga escala (BRASIL, 1990). A partir de 1993, com a conclusão da desestatização do setor siderúrgico, foi intensificado o processo de transferência de empresas produtivas ao setor privado. O Governo buscou ampliar o PND ao introduzir mudanças na legislação que possibilitaram: o uso mais amplo de créditos contra o Tesouro Nacional como meio de pagamento, a venda de participações minoritárias e a eliminação da discriminação contra investidores estrangeiros, passando a permitir sua participação em até $100 \%$ do capital votante das empresas a serem alienadas (PASIN; BORGES, 2003).

Inicialmente limitada à venda de empresas e participações incluídas no PND, a privatização no Brasil adquiriu nova dimensão a partir de 1997. Foram intensificadas as operações em âmbito estadual, com a venda de participações minoritárias em empresas pelos estados. A Lei $n^{\circ} 9.491$ criou o Conselho Nacional de Desestatização (CND), órgão superior de decisão do PND (BRASIL, 1997b). Teve início o processo de privatização do setor de telecomunicações com a realização das primeiras licitações para concessões públicas de serviços fundamentais à sociedade civil, através de parcerias público-privadas, denominadas PPP, além da aprovação, também em 1997, da Lei Geral de Telecomunicações (BRASIL, 1997a), que possibilitou a venda das empresas de telecomunicações de propriedade do governo.

\subsubsection{Mudanças administrativas em}

\section{Minas Gerais}

O Estado de Minas Gerais modernizou sua administração a partir de 2003, através do chamado Choque de Gestão (que seria o primeiro deles, como se verá a seguir), que se encontra dentro do Plano Mineiro de Desenvolvimento Integrado (PMDI). Ele constitui uma forma de administrar que visa melhorar a qualidade dos gastos públicos, gastando menos com a máquina administrativa e mais com a prestação de serviços à sociedade, aumentando, assim, a eficiência da prestação de serviços da administração pública (NEVES in MINAS GERAIS, 2013). 
Afirma Anastasia (2009), recordando o momento de criação do Choque de Gestão, que não se tratava de uma medida demagógica ou sem importância, muito pelo contrário, era um projeto sério e tangível, que se baseava em três pilares: qualidade fiscal, gestão eficiente e resultados. Buscava-se acima de tudo gastar menos e com qualidade.

Com o intuito de tornar Minas Gerais o "melhor Estado para se viver", no ano de 2007, o governo estadual reestruturou o PMDI, criando a segunda geração do Choque de Gestão, que pretendia equilibrar as despesas e as receitas do Estado. Todas estas medidas colaboraram para uma gestão mais eficiente dos recursos públicos destinados a áreas estratégicas da sociedade, como segurança pública, saúde, educação, saneamento básico, e outras áreas imprescindíveis para a administração pública e à sociedade.

De modo geral, tal reforma insere-se dentro de um contexto relacionado com o "esgotamento das condições de financiamento do antigo padrão de industrialização" - que resultou em uma crise fiscal interna e desordem nas finanças públicas. Tal esgotamento estava associado às pressões advindas do "acirramento do processo de globalização, que elevou o nível de competição entre os países e suas empresas, demandando um aumento no padrão de eficiência dos respectivos Estados" (NASSUNO in BRESSER-PEREIRA; GRAU, 1999, p. $335)$.

\subsection{Unidades de Atendimento Integradas (UAIs)}

As centrais de atendimento ao cidadão surgiram no Brasil com as reformas sofridas pelo Estado, na década de 90 do século XX, vindo a se materializar nas redefinições dos papéis da gestão pública no país, culminando em uma melhor gestão dos gastos públicos.

Em Minas Gerais, a primeira versão dessas unidades de serviços se deu por meio da criação dos Postos de Serviço Integrado Urbano (PSIU), instituídas pelo Decreto $\mathrm{n}^{\circ} 38.303$, de 23 de setembro de 1996, sendo que a maior parte dos postos foi inaugurada em 1998 (MINAS GERAIS, 2011a).

OS projetos estruturadores do governo do Estado de Minas Gerais foram fortalecidos a partir do Choque de Gestão denominado de Descomplicar, que tinha, como o próprio nome sugere, o objetivo de simplificar as relações do Estado com 
cidadãos, empresas e o próprio Estado, tendo em vista a construção de um ambiente institucional adequado ao bom desenvolvimento da cidadania, dos negócios e dos investimentos privados (MINAS GERAIS, 2011a).

Assim, com este ambiente favorável, iniciou-se o processo de reestruturação das unidades do PSIU, buscando um modelo inovador de gestão e adotando o conceito dos pontos de atendimento integrados, já existentes em outros estados brasileiros. Uma das mudanças mais significativas foi a mudança do nome, de "Posto de Serviços Integrados Urbanos (PSIU)" para "Unidade de Atendimento Integrado (UAI)". A transição foi feita de forma gradativa em todo o estado e só ocorreu na medida em que os postos foram sendo reformulados (MINAS GERAIS, 2011a).

A premissa básica do PMDI de ter o cidadão como foco das ações do Estado foi uma das motivações para a mudança, que objetivou fazer com que a UAI oferecesse um atendimento rápido, eficiente e adequado.
O Estado construiu, através de edital público, uma modelagem de parceria público-privada (PPP). Isso possibilitou, concomitantemente, uma redução de custos para o Estado e uma reformulação das características gerenciais, técnicas e operacionais do modelo UAI. Garantiu-se, dessa forma, maior flexibilidade gerencial, redução de risco para o Estado, maior padronização de equipamentos, processos e uma estrutura operacional mais adequada à natureza do serviço prestado, comparativamente ao formato de execução direta anterior.

No modelo de execução direta, o Estado arca com a totalidade do custo de implantação das UAIs, ao passo que no modelo PPP, sob o regime de empreitada integral, esse custo é integralmente transferido ao parceiro privado, do qual se exige, ainda, um plano e um cronograma de implantação detalhados, a partir dos quais o Poder Público possa acompanhar o processo (MINAS GERAIS, 2010). Melhoria que se pretende com o novo modelo. 


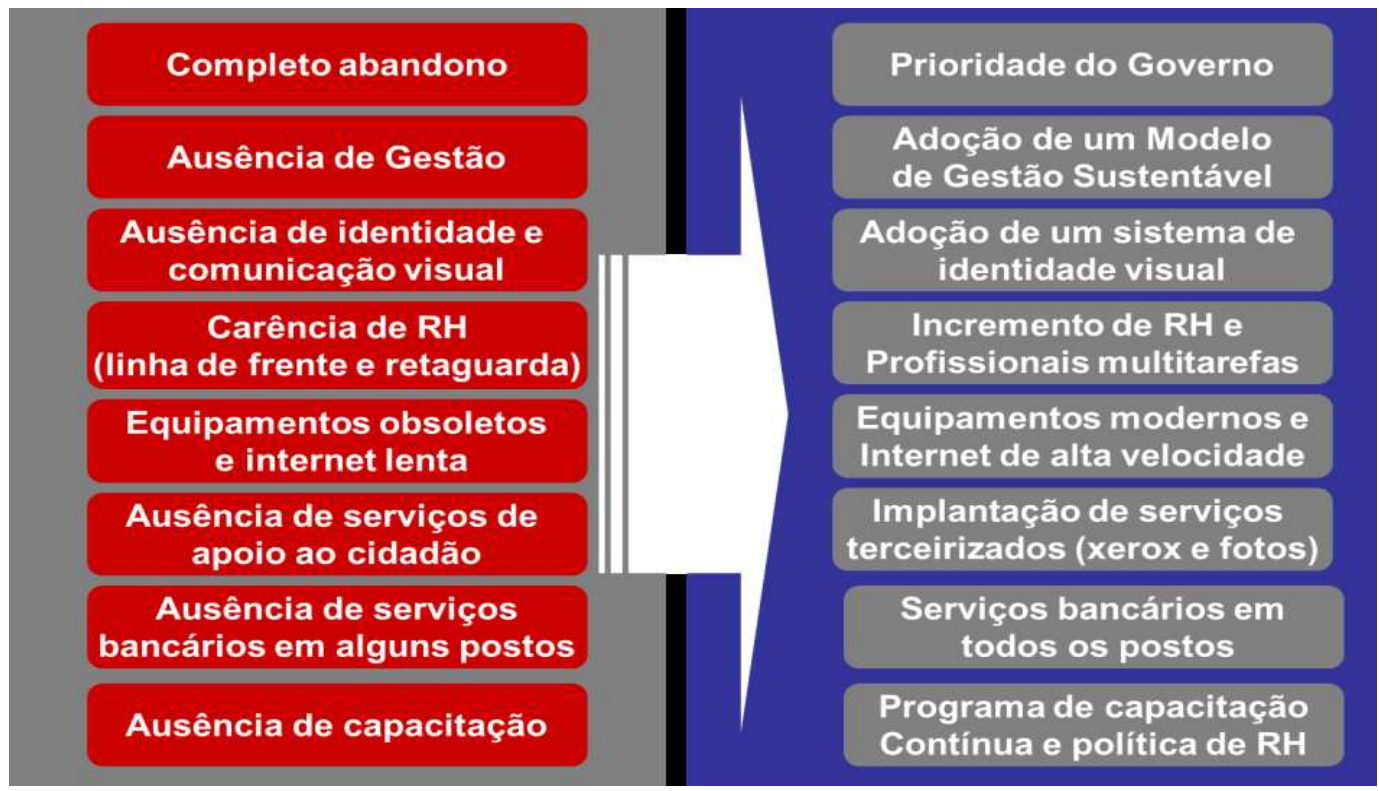

Figura 1 - Comparativo de gestão pública e gestão privada

Fonte: Minas Gerais (2011a).

É Importante reiterar que exercida pela PPP, ambas existem em Minas Gerais dois modelos de gestão para as UAIs: uma puramente exercida pelo governo do Estado e outra desempenhando um papel importantíssimo para a nossa sociedade mineira.

\section{METODOLOGIA}

Foi adotada a metodologia da pesquisa descritiva com abordagem quantitativa, pretendendo-se investigar se, na percepção de satisfação dos usuários/clientes, há diferenças significativas entre a gestão pelo governo ou pela PPP. Assim, tratou-se de investigar as análises sobre os modelos de gestão adotados em Minas Gerais, o estatal e aquele por PPP, obedecem ao quesito de eficiência, demonstrando possíveis distinções na oferta dos serviços quanto à percepção de qualidade de seus clientes/usuários. Utilizou-se do método estudo de campo, que, segundo Vergara (2011), visa obter dados que representem a população a ser analisada, preocupando-se com situações típicas, sendo um pouco mais restrito, com uma profundidade maior.

Para a escolha do universo e amostra foi constituído por 348 usuários/clientes, dividido de forma igualitária, ou seja, 174 usuários/clientes para cada UAI, nos dois modelos de gestão, atingindo uma margem de confiança de $95 \%$ e prevendo uma margem de erro de $4 \%$. 


\begin{abstract}
O objetivo da unidade de análise
é analisar comparativamente as expectativas e percepções da qualidade de serviços entre duas UAIs, sendo que uma delas adota a gestão tradicionalmente pública e a outra aplica o modelo de parceria públicoprivada. Ambas operam na região metropolitana de Belo Horizonte (MG) e são prestadoras do mesmo tipo de serviço.
\end{abstract}

\section{APRESENTAÇÃO E DISCUSSÃO DOS RESULTADOS}

\subsection{Apresentação dos Resultados}

Com as entrevistas era esperado que os participantes relatassem sua percepções da qualidade dos serviços entre duas unidades de UAIs, e se há diferenças significativas entre a gestão pelo governo ou pela PPP. O roteiro do questionário seguiu com questões estruturadas versando sobre qualidade dos serviços, adaptados do modelo proposto por Parasuraman, Zaithaml e Berry (1985), denominado de escala SERVQUAL.
4.1

Caracterização

dos clientes/usuários das duas Unidades de Atendimento Integrado

Os resultados obtidos em relação à Unidade de Atendimento Integrado com gestão pública e àquela com gestão privada (PPP), tendo sido avaliados os critérios gênero, faixa etária, nível de escolaridade e renda. A amostra de 174 entrevistados coletada na unidade pública é composta por $53 \%$ de clientes/usuários do gênero masculino e $47 \%$ do gênero feminino, revelando um equilíbrio entre os gêneros em termos de utilização dos serviços.

No que diz respeito a faixa etária a maioria dos clientes/usuários entrevistados da unidade pública $(54 \%)$ está acima dos 37 anos de idade. Assim, constatou-se que: $12 \%$ dos pesquisados estão na faixa etária entre 16 e 21 anos; $10 \%$ estão na faixa entre 22 a 26; $14 \%$ entre 27 a 31; $12 \%$ na faixa de 32 a 36, $24 \%$ entre 37 e 41 ; e $28 \%$ acima dos 41 anos de idade.

Quanto ao nível de escolaridade dos clientes/usuários entrevistados da unidade pública se concentra (40\%) no Ensino Médio (correspondente ao $2^{\circ}$ grau). Além destes, $21 \%$ têm $1^{\circ}$ grau; $21 \%$ se encontram no $3^{\circ}$ grau; $16 \%$ na pós-graduação lato sensu e $2 \%$ na pós- 
graduação stricto sensu, correspondente ao mestrado.

Com relação a renda da maioria dos clientes/usuários entrevistados da unidade pública $(58 \%)$ possui renda entre 1 a 3 salários mínimos; 39\% de 4 a $6 ; 1 \%$ de 7 a 10 e $2 \%$ acima de 10 salários mínimos.

A respeito do gênero dos respondentes a amostra pesquisada na unidade com gestão privada (PPP) é composta por $52 \%$ do gênero feminino e $48 \%$ do gênero masculino. Percebe-se que, similarmente ao que ocorre na unidade com gestão pública, houve equilíbrio entre os gêneros em termos de utilização dos serviços.

Com relação a faixa etária dos respondentes a maioria dos clientes/usuários entrevistados da unidade com gestão privada (49\%) está acima dos 37 anos de idade, sendo: $21 \%$ entre 16 e 21 anos; $11 \%$ entre 22 e 26 ; $10 \%$ entre 27 e $31 ; 9 \%$ entre 32 e 36; $17 \%$ entre 37 e 41 e $32 \%$ acima dos 41 anos de idade.

A respeito do nível de escolaridade dos cliente/usuários da unidade de gestão privada pode-se perceber que os clientes/usuários entrevistados da unidade com gestão privada se concentram da seguinte forma em relação ao nível de escolaridade: $21 \%$ no $1^{\circ}$ grau; $47 \%$ no $2^{\circ}$ grau; $21 \%$ no $3^{\circ}$ grau, $10 \%$ na pósgraduação lato sensu e $1 \%$ no stricto sensu, correspondente ao mestrado.

A respeito da renda dos usuários da unidade de gestão privada os respondentes revelaram que, dentre os clientes/usuários entrevistados da unidade com gestão privada, $61 \%$ possuem renda entre 1 a 3 salários mínimos; $36 \%$ entre 4 e $6 ; 2 \%$ entre 7 e 10; e $1 \%$ está acima dos 10 salários mínimos.

A análise dos dados revelaram que os valores se comportaram de forma muito equilibrada, não apresentando diferenças significativas, destacando-se uma leve tendência para o modelo público.

\subsection{Descrição dos dados referentes às expectativas e percepções dos clientes/usuários de serviços públicos sobre a qualidade}

\footnotetext{
Os dados apresentados neste item se referem às expectativas $\mathrm{e}$ percepções dos clientes/usuários nos dois modelos de gestão estudados. A média das notas dadas em cada questão mostra o valor de equilíbrio entre os vários clientes/usuários com referência à mesma questão. $\mathrm{O}$ desvio padrão (DP) apresenta a margem de erro, ou seja, o quanto as notas variam em torno da
} 
média. $\mathrm{E}$ a moda mostra a nota mais frequente, isto é, a nota, dada pelos clientes/usuários, que mais aparece em cada resposta.

De modo geral, pode-se afirmar que os clientes/usuários da unidade com gestão privada (PPP) apresentaram expectativas maiores que os clientes da unidade com gestão pública. A mesma relação entre os dois grupos foi obtida no quesito percepções. Percebe-se, então, que os clientes/usuários avaliaram o modelo de gestão PPP com notas maiores que o modelo de gestão pública.

Analisando a dimensão da Tangibilidade, ficou demonstrado que enquanto os clientes/usuários do modelo de gestão privada (PPP) estão preocupados com toda a dimensão Tangibilidade, no modelo de gestão pública os clientes/usuários estão mais preocupados com a praticidade das instalações físicas do que propriamente com a beleza e modernidade.

A respeito da Confiabilidade, os dois modelos de gestão apresentam modas idênticas para todas as questões (igual a 5), revelando que nos dois modelos os clientes/usuários estão preocupados com o nível de Confiabilidade que o setor de serviço impõe. $\mathrm{Na}$ verdade, estão ambos preocupados e desejosos por encontrar um local de trabalho que lhes inspire confiança nos serviços que irão utilizar.

A respeito da dimensão Receptividade em relação às expectativas pode-se verificar, no modelo de gestão pública, que em todas as questões a maior frequência de nota foi 5 (moda 5), enquanto que no modelo de gestão privada (PPP) obtiveram maior frequência de nota 5 (moda 5 ). Isso demonstra que os clientes/usuários do modelo de gestão pública estão preocupados com a forma com que serão tratados ao usarem os serviços, enquanto que os clientes/usuários do modelo de gestão privada (PPP) estão preocupados apenas com a exatidão das informações e a solicitude do funcionário ao atendê-lo. Quanto a serem atendidos de imediato e à disposição para solucionar dúvidas, os clientes/usuários do modelo de gestão privada (PPP) nem sequer criam expectativas, não se preocupam com estas questões.

Quanto às expectativas em relação à dimensão Segurança, os clientes/usuários do modelo de gestão privada (PPP) sentem a necessidade de encontrar um ambiente totalmente seguro no que diz respeito às relações de prestação de serviços, pois em todas as questões a maior frequência de nota foi 5 (moda 5). Já os clientes/usuários 
do modelo de gestão pública desejam um ambiente seguro com relação à confiabilidade do funcionário e nas transações propriamente ditas, que dizem respeito à gentileza no tratamento e ter conhecimento suficiente para responder prontamente suas dúvidas, os clientes/usuários não criam boas expectativas, sendo a maior frequência de notas nestas questões de 2 e 3 , respectivamente.

O critério Empatia para os clientes/usuários do modelo de gestão privada (PPP) é fator necessário, visto que em todas as questões a maior frequência de notas foi 5 (moda 5). Enquanto que os clientes/usuários do modelo de gestão pública não se preocupam muito com os fatores dessa dimensão, já que as modas foram 2 e 1 para todas as perguntas referentes a essa dimensão. Isso demonstra que os clientes/usuários do modelo de gestão privada (PPP) estão mais preocupados com o atendimento individualizado, horários de atendimento compatíveis com sua necessidade, atenção personalizada, que seus interesses sejam priorizados e que os funcionários devam entender suas necessidades; o que não é prioridade para os clientes/usuários do modelo de gestão pública.

Quanto à dimensão

Atendimento, os clientes/usuários do modelo de gestão privada (PPP) esperam mais do setor de serviços que os clientes/usuários do modelo de gestão pública. Esse resultado pode ser inferido a partir das respostas dadas pelos clientes/usuários do modelo de gestão privada (PPP). Assim, os clientes/usuários do modelo de gestão privada (PPP) estão preocupados com a forma com que são atendidos e esperam receber algo a mais do que o proposto, como serviços complementares, informações, procedimentos e eventos, envolvimento da coordenação; o que não constituem preocupações do usuário da gestão pública.

Pode-se perceber que os clientes do modelo de gestão privada (PPP) estão mais preocupados e criam mais expectativas com relação ao fornecimento de serviços que os clientes/usuários do modelo de gestão pública. Verifica-se que os clientes/usuários do modelo público se preocupam mais com a praticidade do fornecimento de serviços que com a forma como eles serão atendidos. Não se preocupam em ter atendimento individualizado, mas sim em serem atendidos e terem seu problema resolvido, mesmo que demore, pois também não é sua preocupação o atendimento imediato, mas sim que seja eficiente o procedimento. 
4.3 Descrição dos dados obtidos a partir da aplicação do método SERVQUAL

Reitera-se a importância da utilização do método SERVQUAL, escolhido para o tratamento e análise dos dados da pesquisa por ser uma ferramenta que compara questões de expectativa e percepção em relação à qualidade nos serviços, sendo estes divididos nas dimensões de tangibilidade, confiabilidade, receptividade, segurança, empatia e atendimento.

Serão utilizados parâmetros para analisar os gaps, avaliando as diferenças entre percepções e expectativas: gaps entre 5 a 3 negativos serão considerados muito ruins em relação à qualidade; gaps entre 3 a 1 negativos serão considerados ruins em relação à qualidade; para gaps entre 1 negativo a zero, considera-se a existência de qualidade, exigindo atenção à questão; para gap igual ou superior a zero, considera-se alta qualidade nos serviços. Ressalta-se que os parâmetros para gap utilizados na análise dos dados foi adaptado de Parasuraman, Zeithaml e Berry (1985), no modelo proposto e denominado de escala SERVQUAL.
Assim, percebe-se que a tangibilidade para o setor público é maior que as demais dimensões, tanto para o modelo de gestão pública quanto para o de gestão privada (PPP). $\mathrm{Na}$ tangibilidade do modelo de gestão pública, o gap está acima de 0,20 positivo; enquanto a média do gap da gestão privada (PPP) é zero, significando que no serviço público a tangibilidade foi percebida com uma qualidade superior que no serviço privado.

Quanto à dimensão confiabilidade, pode-se perceber que, apesar de o gap nos dois modelos ser pequeno, no modelo de gestão pública ele foi negativo enquanto que no modelo de gestão privada (PPP) ele foi positivo; demonstrando que no modelo de gestão pública a expectativa ainda supera a percepção da qualidade nos serviços, relativa à dimensão confiabilidade.

Analisando a receptividade, os gaps se comportaram de forma positiva, prevalecendo o equilíbrio, nessa dimensão, entre ambos os modelos, acima de 0,10, com uma leve superioridade para o modelo de gestão privada. $\mathrm{O}$ resultado significa que em ambos os modelos de gestão as percepções superam as expectativas. 
$\mathrm{Na}$ dimensão segurança, destacam-se gaps inversamente proporcionais para ambos os modelos, apresentando valores positivos para o modelo de gestão pública e negativos para o modelo de gestão privada (PPP); comportando-se os gaps no primeiro modelo $\log$ a abaixo de 0,20 positivo e no segundo modelo abaixo de 0,20 negativo. Isso significa que os clientes/usuários no modelo de gestão privada (PPP) apresentaram expectativa maior em relação ao que foi percebido na qualidade dos serviços. No modelo de gestão pública, a percepção é superior à expectativa, demonstrando que nesta dimensão os clientes/usuários reconhecem que os serviços no modelo de gestão pública são melhores que no modelo de gestão privada (PPP).

A dimensão empatia, assim como foi apresentado na dimensão segurança, os gaps são opostos, favorecendo o modelo de gestão pública, com um gap positivo próximo a 0,10 , enquanto que no modelo de gestão privada (PPP), o gap foi próximo a 0,10 negativo. Com isso pode-se afirmar que, nesta dimensão, os clientes/usuários reconhecem também que os serviços no modelo de gestão pública são ligeiramente melhores que no modelo de gestão privada (PPP).

Ao contrário dos resultados apresentados até o momento, a dimensão atendimento apresentou gaps negativos nos dois modelos de gestão analisados. Foram obtidos valores em torno de 0,05 negativo para o modelo de gestão privada (PPP) e próximo a 0,10 negativo para o modelo de gestão pública, revelando que, em ambos os modelos, as expectativas não são supridas pelas percepções.

Foi constatado, através do método SERVQUAL, que o gap geral dos dois modelos estudados é próximo a ZERO, o que demonstra um equilíbrio entre as expectativas e percepções dos clientes/usuários em relação à qualidade dos serviços, ratificando uma alta qualidade dos serviços prestados nos dois modelos. Porém, há necessidade de se observar com maior atenção o modelo de gestão privada (PPP), já que de forma geral o valor de gap foi negativo; como sugere Parasuraman, Zeithaml e Berry (1985) no modelo proposto e denominado de escala SERVQUAL, conforme apresentado no QUADRO 1. 
Quadro 1 - Relatório geral de gap dos modelos de gestão pública e de gestão privada (PPP)

\begin{tabular}{|c|c|}
\hline Modelo & Gap \\
\hline Público & 0,07 \\
\hline Privado/PPP & $-0,01$ \\
\hline
\end{tabular}

Fonte: Elaborado pelo autor com base nos dados da pesquisa - 2013

Conforme foi comprovado pelo teste estatístico, não existe diferença significativa entre as médias das expectativas nos modelos de gestão pública e de gestão privada (PPP), no nível de significância de 0,05 , o mesmo ocorrendo para as percepções nos dois modelos.

\section{CONSIDERAÇÕES FINAIS}

$\mathrm{Na}$ pesquisa, detectou-se que a expectativa dos clientes/usuários analisados foi similar nos dois modelos de gestão. Os resultados encontrados evidenciam que a maioria dos clientes/usuários possui alta expectativa sobre a qualidade dos serviços prestados pelas Unidades de Atendimento Integradas (UAIs). Já as percepções sobre a qualidade dos serviços possuem diferenças relevantes. Os clientes/usuários do modelo de gestão privada (PPP) percebem menos qualidade sobre os serviços do que os clientes/usuários no modelo de gestão pública. No entanto, em ambas as avaliações, as percepções e expectativas foram consideradas satisfatórias e positivas pelos clientes/usuários dos serviços de modo geral.

Quanto ao objetivo específico "caracterizar os clientes/usuários das duas unidades de atendimento integrado", foi verificado que o perfil deles é semelhante.

Em relação às expectativas e percepções de clientes/usuários dos serviços públicos sobre a qualidade de seus serviços em duas unidades da UAI, identificou-se que existe alta expectativa e percepção entre os clientes/usuários deste modelo de gestão sobre a qualidade de seus serviços. Cabe ressaltar que tanto a média da avaliação da expectativa quanto da percepção demonstraram equilíbrio. Sobre este objetivo pode-se concluir 
que as expectativas dos clientes/usuários do modelo público, bem como dos clientes/usuários do modelo privado são, na sua média, iguais às percepções de qualidade sobre os itens avaliados na pesquisa.

O equilíbrio de resultados entre ambos os modelos pode ter ocorrido pelo motivo de os clientes/usuários não conseguirem distinguir entre as unidades públicas e as privadas, em função de suas instalações físicas serem semelhantes e ainda devido a poucas informações que eles possuem sobre cada modelo na execução dos serviços. O seu desempenho sobre os itens tangibilidade, confiabilidade, receptividade, segurança, empatia e atendimento pode ter sido influenciado pela rigidez burocrática na sua gestão, exigida pelo Estado nos dois modelos estudados, dificultando a implantação de processos e estruturas que propiciem uma qualidade de serviços maior. $\mathrm{O}$ grande desafio é manter ao longo do tempo os padrões de qualidade aferidos, conscientizando o prestador de serviço da sua importância no processo.

Também foi constatado, através dos dois modelos estudados, que a diferença foi próxima a zero, indicando no modelo público um valor de gap de 0,07 positivo, e 0,01 negativo para o modelo privado, o que demonstra um equilíbrio entre as expectativas e percepções dos clientes/usuários em relação à qualidade dos serviços, ratificando uma alta qualidade dos serviços prestados nos dois modelos, como sugere Parasuraman Zeithaml e Berry (1985) no modelo proposto e denominado de escala SERVQUAL.

No modelo de gestão pública foi identificada uma alta qualidade dos serviços avaliados com pontuação SERVQUAL superior à da gestão privada. Este desempenho sobre os itens tangibilidade, confiabilidade, receptividade, segurança, empatia e atendimento pode ser decorrente da maior expertise da organização na gestão desses serviços.

O que pode ter contribuído para o diagnóstico do desempenho levemente superior é o fato de que, diferentemente da gestão pública, a unidade com o modelo de gestão privada sofre mais com o fato da pouca experiência em gerir e estar, de certa forma, competindo pelos serviços com a gestão pública, que dita as regras e procedimentos sobre os serviços ofertados. Neste contexto, a unidade de atendimento privada necessita implantar a cultura de atendimento, levando-se em conta as necessidades dos clientes/usuários neste novo cenário que desponta em seus funcionários por meio da qualidade. 
Concluindo, as dimensões se comportaram durante as análises de forma equilibrada, destacando-se no modelo público as dimensões empatia, segurança, receptividade e tangibilidade, que apresentaram gaps positivos, o que revela uma percepção da qualidade dos serviços superior às expectativas. Apenas atendimento e confiabilidade demonstraram comportamento inverso às demais dimensões, sugerindo que as percepções não atenderam plenamente às expectativas no modelo de gestão pública.

No modelo de gestão privada (PPP), a maioria das dimensões demonstraram gaps negativos. Atendimento, empatia e segurança apresentam valores de gap entre 0,05 e 0,12 negativo, sugerindo que as percepções não se confirmaram em relação às expectativas criadas em torno da qualidade dos serviços pelos clientes/usuários. Porém, o fato de os gaps estarem próximos a zero indicou qualidade nos serviços aceitável, porém com ressalvas, devendo essas dimensões ser posteriormente alvo de melhorias.

Os resultados desta dissertação poderão contribuir para entender e aprofundar os estudos sobre a qualidade de serviços e sua relação com os modelos de gestão analisados - pública e privada. Além disso, as organizações, com base nos dados apresentados, poderão estabelecer melhores práticas de gestão para elevar o desempenho da qualidade de seus serviços para os clientes/usuários.

A limitação deste estudo consistiu no fato de que foram estudadas duas unidades de atendimento integrado. Existem 23 unidades no modelo público e 6 unidades no modelo privado no Estado de Minas Gerais geridas por dois modelos de gestão: um puramente público e outro através de parceria público-privada. Ressalta-se aqui que os resultados encontrados referem-se aos dois pontos de atendimento objetos deste estudo.

A partir dos resultados deste estudo outros pesquisadores poderão continuálo, aprofundá-lo e complementá-lo, reiterando uma das características do conhecimento científico, que é se renovar, modificar e complementar.

A primeira sugestão é a de realizar um estudo mais amplo no sentido de englobar todas as demais unidades de atendimento supracitadas, para traçar o perfil da qualidade de serviços nos dois modelos existentes em Minas Gerais.

Por fim, é sugerido o emprego de outros instrumentos que viabilizem 
uma pesquisa mais detalhada sobre este estudo, utilizando técnicas de levantamento qualitativo para justificar os resultados da pesquisa quantitativa e evidenciar as devidas relações dos resultados encontrados.

\section{REFERÊNCIAS:}

ABRAMS, R. A.; AYERS, C. S.; PETTERSON, M. V. Quality assessment of dental restorations: a comparison by dentists and patients. Community Dent. Oral Epidemiol, v. 4, p. 317-319, 1986.

ANASTASIA, Antônio Augusto Junho. O Estado necessário e a verdade republicana. Revista Del Rey Jurídica, São Paulo, ano XI, n. 21, p. 65, $1^{\circ}$ sem. 2009.

BERRY, L; PARASURAMAN, A. Serviços de marketing: competindo através da qualidade. São Paulo: Maltese, 2006.

BRESSER-PEREIRA, L. C.; SPINK, P. K. (org.). Reforma do Estado e Administração Pública Gerencial. Rio de Janeiro. Fundação Getúlio Vargas Editora, 2008.

CAMPOS, Vicente Falconi. TQC: Controle da Qualidade Total (no estilo japonês). 8. ed. Belo Horizonte: Bloch Editora, 2004.

CASTOR, B. V. J. et al. Estado e administração pública: reflexões. Brasília: FUNCEP, 1987.

CAULLIRAUX, Heitor; YUKI, Mauro (Org.). Gestão pública e reforma administrativa: conceitos e casos: a experiência de Florianópolis. Rio de Janeiro: Lucerna, 2004.
CORRÊA, H. L., CAON, M. Gestão de serviços: lucratividade por meio de operações e de satisfação dos clientes. São Paulo: Atlas, 2006.

COBRA, M. Administração de Marketing. São Paulo: Atlas, 1990.

DONABEDIAN, A. Explorations in quality assessment and monitoring: the definition of quality and approaches to its assessment. Health Administration Press, v. 1, p. 163, 1980.

GIANESI, I. G. N., CORRÊA, H. L. Administração estratégica de serviços: operações para a satisfação do cliente. São Paulo: Atlas, 1996.

GIANESI, I. G. N., CORRÊA, H. L. Administração estratégica de serviços: operações para a satisfação do cliente. São Paulo: Atlas, 1994

GRÖNROOS, C. A. Marketing: gerenciamento e serviços: a competição por serviços na hora da verdade. Rio de Janeiro: Campus, 1995.

JOHNSTON, R., CLARK, G.. Administração de operações de serviço. São Paulo: Atlas, 2002.

KLIKSBERG, B. Redesenho do estado para o desenvolvimento sócioeconômico e a mudança: uma agenda estratégica para a discussão. Revista de Administração Pública, v. 28, n. 3, p. 5-25, jul./set. 1994.

KOTLER, P. Administração de Marketing. São Paulo: Prentice Hall, 2000.

KOTLER, P. Administração de marketing: análise, planejamento, implementação e controle. 5. ed. São Paulo: Atlas, 1998.

LAS CASAS, A. L. Marketing de serviços. 2. ed. São Paulo: Atlas, 2000. 
MELO, Felipe de. Parcerias públicoprivadas e o novo direito administrativo. JusNavigandi, Teresina, ano 9, n. 504, 23 nov. 2004. Disponível em: $<$ http://www1.jus.com.br/doutrina/texto. asp?id=5970>. Acesso em: 17 jun. 2013.

MOORE, Mark H. Criando Valor Público: Gestão Estratégica no Governo. Tradução de P.G. Vilas-Bôas Castro e Paula Vilas-Bôas Castro. Rio de Janeiro: Uniletras; Brasilia, DF: ENAP, 2002.

MUNRO, A. C. M. Divergências entre as expectativas do usuário e a percepção da gerência em relação a qualidade do serviço. 1994. Dissertação (Mestrado em Marketing) - UFRGS, Porto Alegre. Disponível em:

<www.cesusp.ufrgs.br/PPGA/mktres. htm\#15>. Acesso em: 20 abr. 2013. 